\title{
PREDICTION OF ENERGY BALANCE AT THE INDIVIDUAL AND HERD LEVEL BY USE OF BLOOD AND MILK TRAITS IN HIGH YIELDING DAIRY COWS
}

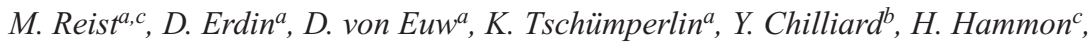 \\ N. Künzi ${ }^{a}$, and J. W. Blum ${ }^{c}$
}

\begin{abstract}
${ }^{a}$ Inst. of Animal Science, Group of Animal Breeding, Swiss Federal Inst. of Technology, CH-8092 Zurich, Switzerland, ${ }^{b}$ Herbivore Research Unit, National Institute for Agricultural Research (INRA), F-63122 St-Genès-Champanelle, France, and ${ }^{c}$ Div. of Animal Nutrition and Physiology, Inst. of Animal Genetics, Nutrition and Housing, Univ. of Berne, CH-3012 Berne, Switzerland
\end{abstract}

Cows expressing severe negative energy balance (EB) postpartum (p.p.) are more susceptible for ketosis, production decline, poor reproductive performance and several health problems. This study aimed to predict individual and herd level EB by use of blood and milk traits in 90 multiparous Holstein cows [mean 9'500 kg energy-corrected milk/305 d], held in a research dairy farm, from wk 1 10 p.p., and to investigate the precision of prediction with reduced data sets, simulating smaller herd sizes, and with pooled samples. Dry matter intake, milk yield and body weight were measured daily from parturition through wk 10 p.p. Milk composition was determined 4 times/wk and milk acetone was measured weekly. Blood samples for the determination of glucose, non-esterified fatty acids (NEFA), cholesterol, creatinine, albumin, urea, b-hydroxy-butyrate (BHBA), leptin, insulin, insulinlike growth factor-1 (IGF-1), growth hormone $(\mathrm{GH}), 3,5,3^{\prime}$-triiodothyronine $\left(\mathrm{T}_{3}\right)$ and thyroxine $\left(\mathrm{T}_{4}\right)$ concentrations, and of activities of aspartate amino transferase (AST), lactate dehydrogenase (LDH) and glutamate dehydrogenase (GLDH) were taken weekly from wk 1-10 p.p. between 0730 - 0900 . Body condition scores and ultrasonic measurements of backfat thickness and fat depth in the pelvic area were evaluated in wk 1, 4, and 8 p.p.. Linear mixed-effects models $(\mathrm{n}=6)$, including blood and milk traits $(n=4)$ or milk traits only $(n=2)$, were developed by backward selection procedures. Results: concentrations of glucose, cholesterol, urea, insulin, IGF-1, T3 and T4 in blood and of lactose and urea in milk were positively correlated with EB, whereas concentrations of NEFA, creatinine, albumin, BHBA and GH and activities of AST, LDH and GLDH in blood and concentrations of fat, protein, fat/lactose ratio and acetone in milk were negatively correlated with EB. Leptin was not correlated to EB over the first 10 wk p.p.. The most informative traits for prediction of EB were NEFA and $\mathrm{T}_{4}$ in blood and the fat/lactose ratio in milk. Inclusion of lactation week and milk yield considerably increased the measures of determination $\left(\mathrm{R}^{2}\right)$ of the explanatory variables, but not the precision of prediction at the herd level. Estimation of EB with milk traits only was as precise as estimation of EB with both milk and blood traits. Stepwise reductions in sample size resulted in increasing losses of precision of prediction. Pooling of the samples resulted in an accurate prediction of the over-all herd EB over the first 10 wk p.p. However, information about EB in individual weeks was lost by pooling the data. The precision of prediction of EB in individual cows was rather low. The measurement of metabolic and endocrine traits is therefore only suitable for evaluation of energy status on a herd level basis. Milk traits information alone, which is easily available, is sufficient for prediction of herd mean EB. 